\title{
Mortality Pattern at Pediatric Intensive Care Unit of Hue Central Hospital, Vietnam
}

\author{
Tran Kiem Hao and Nguyen Huu Son* \\ Pediatric Center, Hue Central Hospital, Vietnam
}

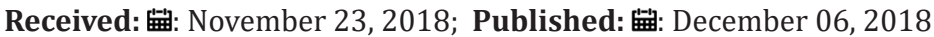

*Corresponding author: Nguyen Huu Son, Pediatric Center, Hue Central Hospital, Vietnam

\begin{abstract}
Objectives: Our aim was to study mortality patterns over a 2-year period in Pediatric Intensive Care Unit (PICU) of Hue Central Hospital, Vietnam.

Patient and method: We retrospectively studied medical record of all children aged 1 month to 15 years old who died in our PICU over a 2 years period (January 2017 - October 2018). Data was collected in a predefined proforma that included age, gender, and final diagnosis at the time of death. Mortality pattern were categorized into 4 groups: (1) Failed cardiopulmonary resuscitation, (2) do-not- resuscitation, (3) brain death, and (4) withdrawal of life-sustaining treatment.

Results: A total of 92 (from an admitted number of 1829) patients died over a period of 2 years with a mortality rate 5.03\%. The median age of children who died was 2.3 years, of which $58.7 \%(n=54)$ were males. The mortality rate was mainly in the age group of less than 12 months $(57.6 \%)$. Model of dealth was failed cardiopulmonary resuscitation and active discontinuation of support in $87 \%$. Brain death was not seen in the study. Most of death cases was beyond 48 hours after admission PICU, approximately 2/3 of the total. Respiratory diseases was the main cause of death (58.7\%).

Conclusions: The infant mortality model at PICU of Hue Central Hospital has changed compared to before, with the increasing occurrence of congenital desease, hereditary, metabolic diseases and very rare diseases.
\end{abstract}

Keywords: Pediatric Intensive Care unit (PICU), Failed Cardiopulmonary Resuscitation, Do-Not- Resuscitation, Brain Death, Withdrawal Of LifeSustaining Treatment

Abbreviation: PICU: Pediatric Intensive Care Unit; CPR: Cardiopulmonary Resuscitation; DNR: Do-not- resuscitation; WLST: Withdrawal of lifesustaining treatment; LST: Life support treatment

\section{Introduction}

The care of critically ill children remains one of the most demanding and challenging aspects in the field of paediatrics. Pediatric intensive care unit (PICU) aims at promoting early intervention and quality care with an objective of achieving good results and better prognosis. This can be achieved by well-equipped and well-staffed intensive care units [1,2]. With the advancement in intensive care facilities, there is a dramatic increase in survival of critically ill children. In critical care medicine, intensive care unit (ICU) results can be assessed on the basis of outcome such as mortality rate or survival. Severity of disease of hospitalized patients has increased over the past decade, and advanced techniques have allowed such patients to stay alive [3]. It is wellknown that advances in medicine and biomedical technology have created the likelihood for medical treatment to be continued beyond a point, of which it offers no advantage to the patient and may lengthen suffering $[4,5]$. It is widely recognized that continued care may not always be advantageous, and this concept has given rise to frequent limitation of life support treatment (LST) [3].

The concept of limitation of LST which includes do-notresuscitate (DNR) and withdrawal of LST (WLST) has examined medical practices to avoid use of treatment which lengthen the patient's life and does not improve the patient's outcomes [6,7]. We could not find any published reports from Vietnam on patterns of mortality among critically ill children in PICU. Therefore, our aim was to conduct a retrospective review on mortality patterns over a 2-year period in PICU of Hue Central Hospital. This assessment can provide valuable inputs in finding local disease pattern as well as cases requiring more intensive management with the aim to predict 
and reduce the mortality. The information thus obtained can also be used to assess the existing services and further improving the facilities for optimum patient care.

\section{Materials and Methods}

We retrospectively reviewed the medical record for all children aged 1-month to 15 years old admitted in the PICU from January 2017 to October 2018. The PICU is belong to Pediatric Center of Hue Central Hospital.

Mortality pattern were categorized into 4 groups:

a) Failed cardiopulmonary resuscitation (CPR),

b) Do-Not-Resuscitation (DNR),

c) Brain Death, and

d) Withdrawal Of Life-Sustaining Treatment (WLST).

The decision of DNR was made by the attending physician after detail discussion and informed consent from parents/guardians. The WLST was done with the involvement of a hospital ethical committee and the attending consultant after obtaining informed consent from parents/guardians. Other data collected from the medial records included patient demographics (i.e. age, sex), diagnosis at the time of death. The cause of death was classified (ICD-10 coding system) on basis of primary system involved.

Statistical analysis was conducted using SPSS, version 19 (IBM SPSS statistics). Descriptive data were reported as means, medians and percentages. The study was approved by the Ethical Review Committee of the Hospital.

\section{Results}

Table 1: Characteristics of children who died in PICU.

\begin{tabular}{|c|c|}
\hline Characteristics & $\mathbf{n = 9 2}(\%)$ \\
\hline Age (year) median (IQR) & 2.3 years (0.3-7 years) \\
\hline$\leq 1$ years & $53(57.6)$ \\
\hline$>1-5$ years & $18(19.6)$ \\
\hline$>5$ years & $21(22.8)$ \\
\hline \multicolumn{2}{|c|}{ Gender } \\
\hline Male & $54(58.7)$ \\
\hline Female & $38(41.3)$ \\
\hline In travel form admission to death \\
\hline Less than 24 hrs & $16(17.4)$ \\
\hline 24 hrs to 48 hrs & $63(14.1)$ \\
\hline More than 48 hrs & $48(52.5)$ \\
\hline \multicolumn{2}{|c|}{ Time of death } \\
\hline Day time & $44(47.8 \%)$ \\
\hline Night time &
\end{tabular}

A total of 1829 children were admitted to the PICU over the 2 years period, of which 92 children died with mortality rate of $5.03 \%$. Most of the children who died were male $58.7 \%(n=53)$ with a median age of 2.3 years (interquartile range $0.3-7$ years), and $77.2 \%$ of children who died were under 5 years old. Most of cases succumbed to death occurred after 48 hours (68.5\%, 63/92). Mortality rate was equal between day time and night time. All the children had initially aggressive supportive care including mechanical ventilation (Table 1). In 52.2\% ( $\mathrm{n}=48)$ children, death was followed by some kind of limitation of life support treatment (LST), which involved do-not-resuscitate (DNR) and withdrawal of LST (WLST) with WLST being more prevalent while in $47.8 \%$ of children $(n=44)$ full resuscitative procedures were carried out. Non of brain death case occurred (Table 2). Most common primary system involved leading to mortality was respiratory system (n $=53 ; 58.7 \%$ ) followed by cardiovascular system ( $\mathrm{n}=11 ; 12.0 \%$ ), central cervous $(n=11 ; 12.0 \%)$ and oncology - hematology $(n=8$; 9.8\%) (Table 3).

Table 2: Modes of death among critically ill pediatric patients in pediatric intensive care unit.

\begin{tabular}{|c|c|c|}
\hline Mode of death & Number of case (n) & Percentage (\%) \\
\hline Brain death & 0 & 0 \\
\hline Failed CPR & 44 & 47.8 \\
\hline Do-not-resuscitate & 12 & 13.0 \\
\hline $\begin{array}{c}\text { Withdrawal of life- } \\
\text { sustaining treatment }\end{array}$ & 36 & 39.2 \\
\hline Total & 92 & 100.0 \\
\hline
\end{tabular}

Table 3: System wise distribution of mortality.

\begin{tabular}{|c|c|c|}
\hline $\begin{array}{c}\text { Primary system } \\
\text { involved }\end{array}$ & Number of case (n) & Percentage (\%) \\
\hline Respiratory system & 53 & 58.7 \\
\hline Cardiovascular system & 11 & 12.0 \\
\hline $\begin{array}{c}\text { Central Nervous } \\
\text { System }\end{array}$ & 11 & 9.8 \\
\hline $\begin{array}{c}\text { Oncology - } \\
\text { Hematology }\end{array}$ & 1 & 1.1 \\
\hline $\begin{array}{c}\text { Endocrine and } \\
\text { Metabolic Disorders }\end{array}$ & 4 & 4.3 \\
\hline $\begin{array}{c}\text { Gastrointestinal } \\
\text { system }\end{array}$ & 2 & 2.2 \\
\hline Others & 92 & 100.0 \\
\hline Total & & \\
\hline
\end{tabular}

\section{Discussion}

The PICU is a special unit primarily concerned with the care of patients with critical illness and demands a broadbased knowledge to achieve good outcome. Advances in pediatric sub-specialties including the critical care medicine have improved the survival of sick children. During the 2 years study period, 1829 children were admitted to the 20 bedded PICU. We report the pattern of mortality among critically ill children admitted to the PICU over a period of 2 years. The mortality rate in our cohort was similar to those reported in US (4-6.2\%) [7-9], UK (5.1\%) [10] and Europe (5.8\%) [3], but lower than those in Canada (7.3\%) [11]. However, one study reported a mortality rate of $13.7 \%$, which was similar to the present findings [12]. The median age of child mortality in the 
PICU in our report was 2.3 years which is similar to other studies ranging from $0.4-8$ year [13]; 0.8 to 3.1 years [3, 10-12], with mostly children under 1 -year of age $(27.9 \%)[10,14]$ or $37.5 \%$ [13] as in our cohort $57.6 \%$.

We identified failed CPR $47.8 \%$ as the most frequent cause of mortality which is similar to the majority of data from international studies followed by the failed CPR [4,5,7, 9-12, 15]. Do-notresuscitate is considered by most authors as an intermediate option between full support of patient and WLST [6]. DNR was the few used form of limitation of LST in our cohort. The variation in the rate of active decision making at end-of-life care may reflect either differences in attitudes and clinical behavior with respect to the active management of dying or may be due to variation in cultures or resources based on the PICU admission criteria whereby children with poor prognosis are not admitted in ICUs [3, 4, 16-19]. Carvalho et al. [20] studied modes of death in PICU of a tertiary hospital shown that, patient age median was 28 months. The cause of death for all patients was multiple organ failure. Twentysix patients (59\%) were classified in group I (not responding to cardiopulmonary resuscitation and brain death) and 18 (41\%) in group II (WLST and DNR). Among patients of group II, 83\% had a chronic and/or debilitating disease $(p=0.017)$.

The prevalent reason for patient admission was the need for organ support $(55 \%)$, both respiratory and cardiovascular. The median for duration of patient stay at the PICU was 5 days and at the hospital was 11 days. There was no statistically significant difference between the two groups in terms of reason for patient admission or duration of PICU/hospital stay. Sands et al. [10] over period of 10 years studied characteristics of deaths in paediatric intensive care, findings showed a median length of stay of 2 days (IQR 0-5 days), with a mortality rate of $5 \%$. The most common mode of death was WLST ( $\mathrm{n}=112,54.9 \%)$ and this was consistent across the 10-year period. Linear regression analysis demonstrated no significant change in trend over the 10 years in each of the modes of death; BD ( $p=0.84)$, WLST ( $p=0.88)$, CPR ( $p=0.35)$ and LST ( $=$ $0.67)$. Studies have shown that children who die after limitation of LST are more likely to have chronic diseases as in Siddiqui's cohort [13] where $72.5 \%$ of patients with chronic diseases had limitation of LST, probably because these children have sufficiently recognized disease, with poor prognosis, and lengthening their lives would sometimes result in unnecessary treatment and needless suffering.

One study showed that parents of children who had chronic disease were more likely to be satisfied with end-of-life care compared with parents whose children had undergone sudden or acute insults. The families of children with chronic conditions may have more time to respond and accept an outcome of death [4]. We observed that respiratory diseases were most common causes of mortality (58.7\%) followed by cardiovascular system $(12.0 \%)$, central nervous $(12.0 \%)$ and oncology - hematology (9.8\%). This observation is consistent with studie of Kapil et al. which reported either sepsis or pneumonia as most common causes of death [21]. Singhal and colleagues in their study found respiratory condition $(40 \%)$ as most common cause of death in their PICU followed by neurological diseases (27\%) [22]. There were several limitations in this study. First, it is a retrospective study which may have some recall and interpretation bias that could lead to incomplete data. Second, we did not examine the discussion between physician and families about end-of-life care. Third, the number of children died in the ward or at home after discharge with a terminal disease, and the patients who stayed alive in spite of limitation of LST (DNR order or WLST) are unknown.

\section{Conclusion}

The low mortality rate indicates optimal quality management of our patients. Most of cases succumbed to death occurred after 48 hours. We found failed CPR as the most common cause of death in our PICU. A higher mortality was associated with more severe conditions of disease and presence of co morbidities. So better care and management should be given for those children admitted to PICU with severe co morbidities.

\section{Acknowledgment}

National Research Council of Sri Lanka (NRC) and the university Grant Commission of Sri Lanka are acknowledged for providing the equipment grants for this research program.

\section{References}

1. Earle M, O Martinez Natera, A Zaslavsky (1997) Outcome of pediatric intensive care at six centers in Mexico and Ecuador. Crit Care Med 25(9): 1462-1467.

2. Young MP, JD Birkmeyer (2000) Potential reduction in mortality rates using an intensivist model to manage intensive care units. Eff Clin Pract 3(6): 284-289.

3. Devictor D, JM Latour, P Tissieres (2008) Forgoing life-sustaining or death-prolonging therapy in the pediatric ICU. Pediatr Clin North Am 55(3): 791-804.

4. Moore P, I Kerridge, J Gillis (2008) Withdrawal and limitation of lifesustaining treatments in a paediatric intensive care unit and review of the literature. J Paediatr Child Health 44(7-8): 404-408.

5. Ryan CA, P Byrne, S Kuhn (1993) No resuscitation and withdrawal of therapy in a neonatal and a pediatric intensive care unit in Canada. J Pediatr 123(4): 534-538.

6. Lago PM, J Piva, D Kipper (2005) Life support limitation at three pediatric intensive care units in southern Brazil. J Pediatr (Rio J) 81(2): 111-117.

7. Vernon DD, JM Dean, OD Timmons (1993) Modes of death in the pediatric intensive care unit: withdrawal and limitation of supportive care. Crit Care Med 21(11): 1798-1802.

8. Mink RB, MM Pollack (1992) Resuscitation and withdrawal of therapy in pediatric intensive care. Pediatrics. 89(5): 961-963.

9. Zawistowski CA, MA DeVita (2004) A descriptive study of children dying in the pediatric intensive care unit after withdrawal of life-sustaining treatment. Pediatr Crit Care Med 5(3): 216-23.

10. Sands R, JC Manning, H Vyas (2009) Characteristics of deaths in paediatric intensive care: a 10 -year study. Nurs Crit Care 14(5): 235-240.

11. Garros D, RJ Rosychuk, PN Cox (2003) Circumstances surrounding end of life in a pediatric intensive care unit. Pediatrics 112(5): e371.

12. Balfour-Lynn IM, RC Tasker (1996) At the coalface-medical ethics in practice. Futility and death in paediatric medical intensive care. J Med Ethics 22(5): 279-281. 
13. Siddiqui NU, Z Ashraf, H Jurair (2015) Mortality patterns among critically ill children in a Pediatric Intensive Care Unit of a developing country. Indian J Crit Care Med 19(3): 147-150.

14. Ramnarayan P, F Craig, A Petros (2007) Characteristics of deaths occurring in hospitalised children: changing trends. J Med Ethics 33(5) 255-260.

15. Martinot A, B Grandbastien, S Leteurtre (1998) No resuscitation orders and withdrawal of therapy in French paediatric intensive care units Groupe Francophone de Reanimation et d'Urgences Pediatriques. Acta Paediatr 87(7): 769-773.

16. Miccinesi G, S Fischer, E Paci (2005) Physicians' attitudes towards endof-life decisions: a comparison between seven countries. Soc Sci Med 60(9): 1961-1974.

17. Sprung CL, SL Cohen, P Sjokvist (2003) End-of-life practices in European intensive care units: the Ethicus Study. JAMA. 290(6): 790-797.

ISSN: 2574-1241

DOI: 10.26717/BJSTR.2018.11.002155

Nguyen Huи Son. Biomed J Sci \& Tech Res

(C) (P) This work is licensed under Creative

Submission Link: https://biomedres.us/submit-manuscript.php
18. Vincent JL (1999) Forgoing life support in western European intensive care units: the results of an ethical questionnaire. Crit Care Med 27(8): 1626-1633.

19. Yaguchi A, RD Truog, JR Curtis (2005) International differences in endof-life attitudes in the intensive care unit: results of a survey. Arch Intern Med 165(17): 1970-1975.

20. Carvalho PR, TS Rocha, AE Santo (2001) Modes of death in the PICU of a tertiary care hospital. Rev Assoc Med Bras (1992) 47(4): 325-331.

21. Kapil D, A Bagga (1993) The profile and outcome of patients admitted to a pediatric intensive care unit. Indian J Pediatr 60(1): 5-10.

22. Singhal D, N Kumar, JM Puliyel (2001) Prediction of mortality by application of PRISM score in intensive care unit. Indian Pediatr. 38(7): 714-719.

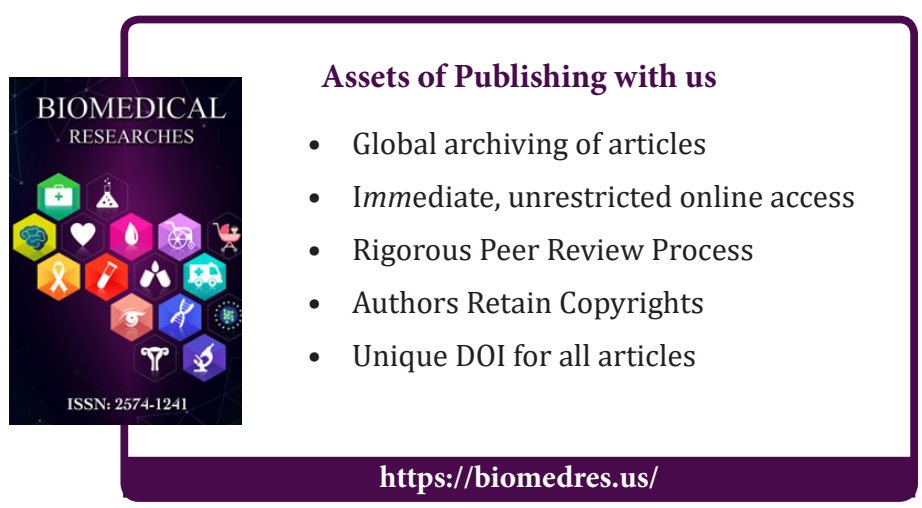

Cite this article: Tran Kiem Hao, Nguyen Huu Son. Mortality Pattern at Pediatric Intensive Care Unit Of Hue Central Hospital, Vietnam. Biomed 